\title{
TRABALHO, VIDA RURAL E EDUCAÇÃO
}

\author{
Ana Elizabeth Santos Alves ${ }^{1}$
}

\section{RESUMO}

$\mathrm{O}$ artigo discute a centralidade do trabalho e da educação na vida de moradores de comunidades rurais, especialmente de mulheres, em narrativas acerca de ações e relações no grupo familiar apreendidas nas contradições históricas da realidade brasileira. Foram realizadas observações exploratórias e entrevistas com 23 grupos familiares, em 2012 2013, no município de Planalto, na Bahia. Utilizou-se, como fonte de dados empíricos, para a análise apresentada neste texto, a história de vida de uma das mulheres entrevistadas, representativa do conjunto do universo investigado. $\mathrm{O}$ enfoque teórico orientou-se pela compreensão do trabalho, da divisão sexual do trabalho e da educação como fenômenos sociais e históricos, articulados com o processo de acumulação capitalista. Observou-se o ciclo de vida familiar na sua inter-relação com as categorias de análise, mediadas pela narrativa de uma história de vida.

Palavras-chave: Trabalho e Educação; Comunidades rurais; Divisão sexual do trabalho.

\section{WORK, RURAL LIFE AND EDUCATION ABSTRACT}

\begin{abstract}
The work discusses the centrality of work and education in the lives of residents of rural communities, especially women, in narratives concerning actions and relations in familiar groups, learned in the historic contradictions of Brazilian reality. Explanatory observations and interviews were performed with 23 familiar groups, in a period between 2012 and 2013, in the municipality of Planato, state of Bahia. The source of the empirical data considered in the analysis presented in the current text is the life history of one of the interviewed women that is representative of the investigated universe. The theoretical focus was driven by the comprehension of work, sexual division of work and education as social and historical phenomena related to the capitalist accumulation process. Observations concern familiar life cycle regarding its relation to the analyzed categories, mediated by a life history narrative.
\end{abstract}

Keywords: Work and Education; Rural Communities; Sexual Division of Work 


\section{Introdução}

O presente artigo resultou de pesquisa ${ }^{2}$ realizada sobre as condições de trabalho e as possibilidades educacionais de mulheres e homens no núcleo de produção familiar em quatro comunidades localizadas na zona rural do município de Planalto, Bahia, levando em consideração aspectos relacionados à história de vida produtiva e reprodutiva ${ }^{3}$. Nessas comunidades, vivem 28 famílias de pequenos agricultores proprietários de pedaços de terra com, aproximadamente, $48 \mathrm{~m}^{24}$. Realizamos observações exploratórias e entrevistas com 23 grupos familiares ${ }^{5}$, ouvindo mulheres (esposas e filhas) e homens (maridos, pais e avôs) que estavam em casa nos dias das nossas visitas, em 2012 e $2013^{6}$. Produzimos o vídeodocumentário "A luta da vida da gente: história, trabalho e educação em comunidades rurais", com narrativas dos moradores sobre o ciclo de vida familiar - trabalho, educação, divisão sexual do trabalho e tempo livre. $\mathrm{Na}$ análise das entrevistas, especialmente com as mulheres, flagramos relatos com reflexões que traduzem o processo de precariedade das condições de vida e de trabalho, tanto materiais e técnicas, quanto educacionais e sociais ${ }^{7}$.

O objetivo deste artigo é apresentar a análise acerca da centralidade do trabalho e da educação na vida dos sujeitos, por meio das narrativas acerca de ações e relações no grupo familiar, que podem ser apreendidas nas contradições históricas da realidade brasileira. Utilizamos, como fonte de dados empíricos, a biografia de uma das mulheres entrevistadas representativa do conjunto do universo investigado. $\mathrm{O}$ enfoque teórico orientou-se pela compreensão do trabalho, da divisão sexual do trabalho e da educação como fenômenos sociais e históricos, articulados com o processo de acumulação capitalista. Em reuniões com os pesquisadores, os participantes da pesquisa tiveram amplo acesso aos objetivos do estudo e assinaram o Termo de assentimento livre e esclarecido. Mantivemos os nomes originais das mulheres entrevistadas e resguardamos, no processo de transcrição das falas, a linguagem própria dos moradores. O nosso compromisso ético na investigação científica foi com a "dignidade da pessoa humana" (CURY, 2015), princípio básico exposto na Constituição brasileira. O planejamento e o desenvolvimento da pesquisa foram guiados por esse princípio e pelo cuidado em lidar com pessoas, especialmente as famílias das comunidades rurais pesquisadas.

$\mathrm{Na}$ primeira parte do texto, apresentamos e caracterizamos as comunidades rurais no contexto geral da sociedade brasileira, articulando com algumas considerações sobre educação, trabalho e divisão sexual do trabalho. Na segunda, ressaltamos o ciclo de vida familiar na sua inter-relação com as categorias de análise, mediadas pela narrativa de uma história de vida.

\section{As Comunidades ${ }^{8}$ Rurais}

As comunidades rurais situam-se a, aproximadamente, $15 \mathrm{~km}$ da sede de Planalto, município baiano, que, do ponto de vista social e econômico, segundo dados do IBGE (2003), apresenta um coeficiente de incidência de pobreza acima de $50 \%$, índice superior à média nacional do Brasil, que é de 32,6\%, e um dos mais baixos da Bahia.

A visão da paisagem na estrada de "chão" (terra batida, cascalho) em direção às comunidades é de uma vegetação típica de região semiárida. As imagens mostram a região de caatinga, no tempo da seca, com a paisagem esbranquiçada e prateada das plantas sem folhas e, no tempo da chuva, uma vegetação com novas folhas e flores. No percurso na estrada, observamos alguns bovinos e o verde das árvores misturado com as flores 
amarelas do Canjoão ${ }^{9}$ e vermelhas do Flamboyant. Predomina umrelevo formado por ladeiras e morros, onde não existe mais resquício das matas originais.

As comunidades visitadas caracterizam-se como de agricultura camponesa tradicional, conforme Wanderley (1996), em que a produção de subsistência é gerida pela família e organiza-se em torno da posse de um pequeno pedaço de terra, do trabalho e do consumo.O grupo familiar (grupo doméstico) é constituído pela família nuclear e parentes,como sogro e sogra, filhos e filhas, genros, noras, netos e netas. Os membros da família buscam condições materiais que garantam a reprodução social do grupo. Schneide e Niederle (2008, p. 992) caracterizam a organização social e econômica da agricultura familiar como "fortemente influenciada por relações de consanguineidade e parentesco". O modo como as famílias gerenciam os recursos materiais e os valores culturais define a indentidade camponesa, porquanto é importante considerar as diferentes formas com que o mundo rural se expressa na representação da pluralidade, isto é, a "existência de ruralidades" (MOTA e SCHMITZ, 2010, p. 94).

O acesso a capital produtivo é quase inexistente. As famílias vivem das transferências sociais de renda, do trabalho temporário na roça de subsistência (ou nas plantações de café) e da ocupação em atividades fora da roça (atividades não agrícolas), a exemplo da construção civil, trabalho doméstico, artesanato e comércio. As análises de Schneide e Niederle (2008, p.995) sobre o sistema produtivo da agricultura familiar contribuem para entender a organização do trabalho nas comunidades analisadas. Os autores explicam que,na medida em que a unidade de producão familiar sofre pressões sociais e econômicas, a exemplo de baixa remuneração do trabalho e de uma vida marcada pelo acesso precário a bens materias, há comprometimento das características originais e "mercantilização das relações sociais" em razão da crescente inserção produtiva da família no mercado capitalista como força de trabalho.

Chamam a atenção de quem visita o lugar os campos vazios e, nas casas, a presença de mulheres e pessoas idosas, anunciando que os moradores, principalmente os jovens, teriam ido trabalhar em outros lugares. A escassez de chuva, a precariedade da vida e o desconhecimento técnico-agrícola transformam mulheres e homens, por meio de uma educação ligada à cidade, em um "elo vivo e ativo das migrações temporárias" (MARTINS, 2004-2005, p.30). O ciclo de vida dos moradores, ao mesmo tempo em que os faz presentes na localidade de moradia, os distancia em busca de trabalho. Um dos principais responsáveis por esse deslocamento do campo para a cidade é o processo de expropriação territorial dos camponeses, um perverso processo social que desestrutura o universo das relações pessoais dos indivíduos. (ALVES e ALMEIDA, 2014, p.256).

O modelo de modernização da agricultura brasileira privilegiou as grandes propriedades e não estimulou a inserção do capital para pequenos proprietários e desapropriados em forma de investimentos em maquinarias e uso de tecnologias de produção (WANDERLEY, 2009). Além disso, as elites capitalistas sempre buscaram controlar a força de trabalho com a formação de um exército de reserva de desempregados ou subempregados. Silva (2001) constatou, em pesquisas, o aumento do número de pequenas propriedades rurais que têm muito mais a função de residência do que de um estabelecimento agropecuário produtivo. Geralmente permanecem na propriedade os pais ou um dos filhos, que cuidam das atividades, enquanto os outros membros da família buscam formas de integração produtiva.

A região nordestina apresenta o maior percentual de pobreza rural do Brasil, e metade desse contingente é formada por agricultores familiares, sendo que "[...] $75 \%$ destes estão nas piores terras do semiárido brasileiro e com áreas inferiores a cinco hectares" (DIAS, 2014, p. 224). 
Pesquisas realizadas por Nascimento (2004) relataram o aumento do número de famílias que desenvolvem atividades não agrícolas no Nordeste, onde não há investimento em tecnologias, há dificuldades em produzir na própria terra e onde ocorre, ao mesmo tempo, um movimento contrário de regresso ao campo em função do desemprego e de constituir-se alternativa segura para a velhice. Martins (2004-2005) acrescenta o fato de as políticas sociais estarem proporcionando o retorno ao campo.

As relações entre educação, trabalho e vida cotidiana nas comunidades são marcadas pela diversidade de estratégias de reprodução social atreladas ao desenvolvimento capitalista. Articulam-se, no núcleo de produção familiar, o trabalho doméstico (o cuidado com a casa, as crianças, os velhos e o quintal), o trabalho na roça, as atividades desenvolvidas fora da roça e as atividades não agrícolas. Nas relações entre homens, mulheres e crianças nas dimensões do trabalho no espaço rural, doméstico e extradoméstico, é que acontecem os processos educativos. A garantia de sobrevivência das famílias tem como eixo central a transmissão de experiências, de práticas de educação e trabalho entre os membros. A educação não está separada da vida e do trabalho. (ALVES, 2013).

Os moradores das comunidades são trabalhadores que lutam e sonham no movimento daqueles que são obrigados a sair temporariamente para vender a força de trabalho em outras regiões na atividade agrícola ou em atividades diversas; dos que fazem o movimento inverso de retorno ao lugar e garantem a sobrevivência por meio de transferências sociais e em ocupações não agrícolas; e daqueles que nunca saíram do lugar e sempre viveram do trabalho temporário da roça, do trabalho artesanal e doméstico, como é o caso da história de vida ${ }^{10}$ de uma das mulheres entrevistadas e do seu marido, cujos filhos desempenham ocupações não agrícolas na cidade.

\section{Ciclo De Vida Familiar: as contradições do trabalho e da educação}

Uma das dimensões importantes na vida dos agricultores camponeses, conforme Wanderley (1996, p.13), encontra-se na necessidade de construir “um 'território' familiar, um lugar de vida e de trabalho capaz de guardar a memória da família e de reproduzi-la para as gerações posteriores.”. O ciclo de vida dos moradores das comunidades rurais envolve situações de migração de membros da família que tiveram de vender a força de trabalho e de se submeter ao trabalho assalariado como meio de garantir a sobrevivência. Neste caso, a vontade de retornar ao lugar sempre é uma esperança, com o objetivo de reconstruir a vida ao lado da parentela. Mas, também, envolve situações de resistência com o envolvimento de grupos familiares em trabalhos de subsistência ou em trabalhos temporários em propriedades vizinhas.

Historicamente, no Brasil, as grandes propriedades sempre ocuparam um lugar de destaque, herança do período colonial que perpassa as transformações sociais e políticas ocorridas na sociedade ao longo do tempo. Basta olhar atentamente a história para identificar, na política agrícola desenvolvida no país, em vários momentos, o direcionamento de estímulos sociais e econômicos para as grandes propriedades com o intuito de defendê-las e mantê-las em posição de privilégio.

Os grupos familiares estudados estão inseridos no lugar do não privilégio, da dominação, assim como os camponeses que, em geral, ocupam um lugar secundário na sociedade brasileira - um lugar historicamente construído. Nas palavras de Wanderley (1996, p.15): 
$\mathrm{O}$ acesso à terra foi, aqui, doloroso e restrito, do que resultou, para a historiografia analisada, as características principais do campesinato brasileiro em sua origem: a pobreza, o isolamento, a produção centrada na subsistência mínima e a extrema mobilidade espacial.

As relações entre a educação e o trabalho das famílias são construídas e desconstruídas no movimento ao longo do ciclo de vida, cujo exemplo pode ser observado na história de vida de uma das mulheres entrevistadas (dona Neuza) e de sua família.

Dona Neuza nasceu em 1961, mora com o marido em uma das comunidades rurais analisadas, teve 7 filhos, destes, 6 estão vivos. A casa é o exemplo do modo simples e provisório de vida das famílias pobres do meio rural: o telhado de telha à vista e meias paredes entre os cômodos; na cozinha, o fogão a lenha (na copa há um fogão a gás) cujo uso intenso é conferido nas paredes manchadas de carvão e no contraste com o brilho das panelas de alumínio bem areadas. Os retratos na parede com fotos da família e da formatura dos filhos no ensino médio se misturam com imagens de santos. A visão da antena parabólica, da TV e do telefone celular evidencia a não separação entre o urbano e o rural, entre o tradicional e o moderno. Os instrumentos de trabalho continuam sendo a enxada, a foice, a pá. O modo de viver segue os costumes típicos da cultura nordestina, que lembram o tempo das chuvas, o tempo do São João; porém, o modo de agir, de vestir dos jovens e os artigos dentro de casa sofrem influências da vida da cidade, as quais unem as pessoas das comunidades ao mundo globalizado. O consumo dirigido dessas mercadorias cria a fantasia de ascensão social e de inclusão das pessoas "nos processos econômicos, na produção e na circulação de bens e serviços, estritamente em termos daquilo que é racionalmente conveniente e necessário a mais eficiente (e barata) reprodução do capital". (MARTINS, 2012, p. 20); além disso, o consumo de produtos comprados alimenta parte do capital variável global (VÈRGES, 2011).

Dona Neuza revela com orgulho a história da sua luta diária. Trabalha em casa no serviço doméstico, cuida, dois dias na semana, da casa do patrão do marido e fabrica, em casa, vassouras de palha, que vende a 3,00 reais a unidade. Afora a renda das vassouras, ela recebe Bolsa Família"11. Em palavras próprias: “[...] A verdade aqui dentro de casa eu não fico parada. Se eu não estou fazendo as minhas vassouras, eu tou no mato tirando paia (palha) para deixar ali para secar (...); quando eu não tou tirando as paias, eu estou tirando as embiras..." para amarrar as vassouras. Ela diz que o marido ajuda quando precisa no serviço doméstico. Quando o marido adoeceu e precisou fazer cirurgia, ela cuidou de tudo, “(...) até madeira de roça, eu tirei. Só nunca fiz uma cerca, porque isso aí eu nunca tentei fazer, não. De roça, só não sei roçar; o mais, tudo eu sei fazer”.

O trabalho é central na história de vida de dona Neuza. A medição do tempo dela e do marido está relacionada aos processos familiares entre o ciclo reprodutivo dos trabalhos domésticos e das atividades produtivas. Ela confecciona vassouras com a cooperação do marido, ajuda ${ }^{12}$ no desenvolvimento das atividades dele e trabalha duas vezes por semana no serviço doméstico remunerado. O tempo que surge nesse contexto, como explica Thompson (2010, p. 271), é orientado pelas tarefas e parece não haver separação entre o " "trabalho e a vida'. As relações sociais e o trabalho se confundem - o dia de trabalho se prolonga ou se contrai segundo a tarefa - e não há grande senso de conflito entre o trabalho e o passar do dia". Há momentos de intensas atividades, uma vez que o trabalho rural é diário, sem pausa aos domingos ou feriados; mas há, também, momentos de ociosidade "para tomar o sagrado cafezinho", como conta o marido de dona Neuza. O descompasso desse ritmo é dado pelo exercício do trabalho assalariado para terceiros.

$\mathrm{Na}$ dimensão do desenrolar do trabalho doméstico e do produtivo, observamos o trabalho árduo e prolongado da mulher. Se centrarmos a nossa a atenção, como sugere 
Hirata (2002), nos processos de trabalho, não devemos nos esquecer da interdependência entre a vida profissional e a vida familiar das mulheres. Na análise dessa questão, é possível considerar dois aspectos. Primeiro, segundo Thompson (2010), é importante observar que a orientação do trabalho feminino em casa não pode ser medida pelo relógio. Outro aspecto é o princípio que indica a existência de trabalhos de homem e trabalhos de mulher (PAULILO, 1987), introduzindo o critério de trabalho leve, atribuído às mulheres, e trabalho pesado e de maior responsabilidade, atribuído aos homens. As atividades desenvolvidas por dona Neuza desnaturalizam esse princípio.

A força física é um dos critérios que explicam, segundo o senso comum, os diferentes papéis exercidos na sociedade por homens e mulheres e organizam a divisão sexual do trabalho. A reconstituição de conteúdos do trabalho, com o discurso de adequação natural de "masculino" e "feminino", em conformidade com o sexo biológico, produz a ideia de "trabalho leve" igual a trabalho de mulher e "trabalho pesado" igual a trabalho de homem.

A divisão de atividades nos espaços de trabalho assim como a concepção de trabalho são reconstruídas, portanto, as qualidades pesado ou leve são representações, uma vez que, quando se verificam mudanças no desenvolvimento das atividades entre homens e mulheres, conforme podemos observar ao longo da história das mulheres, o mesmo "trabalho pesado", que, antes era desempenhado por homens, passa a ser considerado "trabalho leve" quando assumido por mulheres, de acordo com pesquisa desenvolvida por Maia (2004) no Vale do Jequitinhonha (MG).

Diante dessas considerações, buscamos compreender as relações que se estabelecem entre educação e trabalho.

A multidimensionalidade das atividades mostra as práticas de trabalho do cotidiano rural como "tradição do estar junto no trabalho como modo de trabalhar" (MARTINS, 2004-2005, p.34)e reúne a família em torno de diversas funções, integrando funções domésticas com trabalho produtivo. Do convívio dessas práticas de trabalho, podemos compreenderas relações entre educação, trabalho e divisão sexual do trabalho.

Educação significa ato ou efeito de educar (-se) (FERREIRA, 1975, p.499). Etimologicamente, origina-se da palavra educar, do latim educare, educere, cujo sentido é nutrir e alimentar algo, como também fazer esse algo sair. É um fenômeno humano. (EVANGELISTA e MACHADO, 2000, p. 118). Por essa definição, entendemos que a palavra tem um significado amplo,abrange as formas como as pessoas transformam o mundo em que vivemos, criam as coisas e se reproduzem como seres humanos. Por meio "da consciência de si mesmo, o homem se torna criador de si próprio, (...). Ele produz a sociedade, e é por ela produzido, como a sociedade mesma produz o homem e por ele se vê produzida.”. Na relação com a natureza e a sociedade é que o homem se distingue dos animais na medida em que torna a vida objeto de sua consciência (HEYDORN, 1968, p. 110) e em que ocorre o desenvolvimento das capacidades humanas. Nesse processo, encontramos a inter-relação com o trabalho.

O trabalho como conceito antropológico, segundo Marx (1985), é um ato de mediação entre os homens e a natureza, que ultrapassa a atividade instintiva dos animais, convertendo-se na força pela qual a humanidade criou o mundo que conhecemos. A vida do ser humano é permeada por necessidades de sobrevivência e atividades de criação. Mulheres e homens usam sua capacidade mental, os instrumentos e as matérias-primas com o objetivo de transformar a natureza em coisas úteis. Se o trabalho é a relação do homem com a natureza, podemos entender esta relação como um processo educativo.

Ao mesmo tempo, é fundamental considerar que essas relações se estabelecem em condições sociais determinadas. No modo de produção capitalista, os indivíduos trabalham 
sob o controle do capitalista e perdem a propriedade dos meios e instrumentos e o produto do seu trabalho (MARX, 1985). Nessas condições, podemos situar o trabalho assalariado, que produz valores de uso - "trabalho útil" ou "trabalho concreto"; e valores de troca "trabalho abstrato," como dispêndio de força de trabalho humano sob relações econômicas e sociais definidas, independentemente de características específicas ou do que é produzido. (BOTTOMORE, 1988). O "trabalho concreto" e o "trabalho abstrato" não constituem momentos estanques, separados; eles formam a mesma unidade com diferentes aspectos de uma dada atividade.

Além disso, vale acrescentar a essa dupla definição de trabalho, ao lado da mediação entre homem e natureza e a criação de valores de uso e de troca, a existência de relações sociais entre homens e mulheres, enfatizando que “(...) não existem trocas genéricas entre o homem e a natureza, mas trocas sempre específicas entre os homens e as naturezas. E os próprios homens são os homens e as mulheres: assim, torna-se possível falar de sexo do trabalho". (HIRATA e ZARIFIAN, 2009, p. 252). Ao conceituar trabalho, devemos incluir uma massa de trabalho invisível realizado por mulheres, chamando a atenção, assim, para a dimensão sexuada (KERGOAT e HIRATA, apud HIRATA (2002)

Em qualquer trabalho, ocorre o envolvimento entre mente e corpo, portanto, no decorrer das práticas de trabalho, "há produção de bens materiais, mas também construção de representações e saberes, ou seja, de habilidades técnicas, saberes sobre o trabalho e sobre as relações em que se produz o trabalho e o trabalhador", constituindo momentos de formação e aprendizagens (MANFREDI, 2007, p. 27).

Na roça, "o educar não está separado, nem pode estar do viver", do trabalhar, que reúne o grupo familiar (MARTINS, 2004-2005, p. 34) e é,nesse processo,que se formam os valores sobre o trabalho, as tradições culturais e ocorre a construção social e histórica de gênero, segundo o qual delegam-se, aos homens, as atividades produtivas e, às mulheres,os serviços domésticos. Essa divisão do trabalho, entretanto, não é tão visível nas atividades desenvolvidas na roça, pois existe uma relação muito próxima entre o serviço doméstico e as atividades de produção. Ao mesmo tempo, o trabalho na roça é construído por formas de exploração e alienação. A garantia da subsistência das famílias é dada pelo assalariamento permanente ou temporário na época de colheitas ou em outras atividades, como é o caso de dona Neuza, que complementava a renda no trabalho como meeira e, hoje, no trabalho doméstico remunerado.

O trabalhador rural, mesmo que tenha posse de um pedaço de terra, na maioria das vezes é prejudicado na realização das atividades ou, até mesmo, impossibilitado de realizálas em razão das condições climáticas enfrentadas pelos períodos prolongados de seca e, principalmente, pelas condições econômicas, uma vez que lhe são expropriados os meios e os objetos do trabalho, isto é, o controle do seu trabalho é transferido para quem detém a propriedade dos meios de produção.

Dona Neuza conta que, desde mocinha, começou a trabalhar na roça, na lavoura, a "rastar enxada" com os irmãos e os pais. A terra era dos pais. O pai era carpinteiro e, com os ganhos, comprava mercadorias para o consumo da família; o trabalho na roça garantia os alimentos. Depois de casada, continuou a trabalhar na roça do pai junto com o marido e, para completar a renda, saíam para trabalhar como meeiros em terras de outros. As gravidezes não foram empecilhos para continuar a labuta. Os primeiros filhos (um menino e uma menina), enquanto pequenos, eram levados no braço para a roça. Quando cresceram, ficavam em casa para tomar conta dos irmãos mais novos, buscar água e preparar a comida para alimentar a família. Ela passava o dia inteiro na roça capinando, ao sol quente e, segundo ela, para ganhar uma "mixaria". Com muitas dificuldades, muitas economias e, com o comércio de troca de animais, a família conseguiu comprar um pedaço de terra, o 
que consolidou o esforço de assegurar um lugar seguro para a reprodução da família, embora a posse da terra, apenas, não garanta as condições materiais para $\mathrm{o}$ desenvolvimento de uma atividade agrícola produtiva. A agricultura está submetida à exploração e ao controle de preços das grandes indústrias de máquinas, de agrotóxicos, de sementes e ao avanço da concentração fundiária sob o domínio do capital.

As atividades de trabalho no mundo rural, como explica Martins (1975; 20042005), contemplam as etapas de vida das pessoas,ou seja, se iniciam na infância e vão até a velhice, reunindo pais e filhos. É dessa forma que "se educa e protege a criança no campo" (MARTINS, 2004-2005, p. 34). A vivência de práticas de trabalho, como a participação da criança em "pequenas atividades ligadas ao cuidado e à produção da vida" (FRIGOTTO e CIAVATTA, 2012, p.748), constitui um ato educativo. Porém, se as relações de trabalho assumem formas degradantes, de exploração e o trabalho se transforma em assalariado, alienado, temporário e exige a participação de toda a família para atender às necessidades de subsistência, deixa de ser educativo. O problema do trabalho infantil é o fato de coibir as crianças do tempo para o lúdico, privá-las de condições materiais e do acesso ao saber oferecido pela escola, pela família ou por outros educadores da comunidade. (MARTINS, 2004-2005). Além disso, o desenvolvimento do trabalho pesado, que deve ser uma responsabilidade do adulto, a exemplo do transporte de água, do manuseio com o fogão, "compromete ou deforma o desenvolvimento físico, social e psíquico da criança. " (FRIGOTTO e CIAVATTA, 2012, p.753).

Hoje, dona Neuza afirma que não pode mais passar o dia inteiro em atividade na roça, pois não tem quem cuide da casa. Das filhas que a ajudavam, duas se casaram, e a outra trabalha na cidade. O marido trabalha na terra deles e na de outros; aos sábados, vende verduras e aves na feira livre da cidade. Parece que a posse da terra, a soma dos rendimentos de políticas sociais com as atividades temporárias e o trabalho dos filhos aumentaram os ganhos da família.

Observamos que a casa ainda é concebida como um espaço a ser cuidado pelas mulheres, sugerindo uma divisão sexual do trabalho, com a constituição de lugares distintos para mulheres e homens, em que pese à ajuda do marido nos serviços domésticos. A educação transmitida pelas famílias desempenha um papel central na formação dos comportamentos femininos e masculinos, tendo em vista processos educativos gerais que perpetuam o desenvolvimento do trabalho doméstico como trabalho de mulher. (CUNHA e ALVES, 2014).

Quando perguntamos a dona Neuza sobre a educação recebida, respondeu que estudou até a cartilha e, depois, teve de abandonar a escola para trabalhar na roça. Aprendeu somente a fazer o nome. Na época da infância de dona Neuza, os pais impunham aos filhos a permanência na escola a fim de alcançar objetivos "extremamente limitados, e totalmente discrepantes em relação às expectativas do educador, como no caso dos que mandam os filhos à escola para que aprendam a assinar o nome" (MARTINS, 1975, p. 89). E essa foi a experiência de dona Neuza. $\mathrm{O}$ autor ainda explica que o conteúdo ensinado na escola rural e as referências dominantes em relação à classe social do professor não tinham significado em relação às expectativas do mundo rural, especialmente no que diz respeito à equivalência com o trabalho. A aceitação da escola vai depender das relações que cada família tem com a economia de mercado, uma vez que o conteúdo ensinado na instituição estabelece uma equivalência com a realidade do mundo urbano.

Ademais, o histórico atraso educacional das populações rurais no Brasil tem o latifúndio como principal responsável estrutural, segundo Ferraro (2012, p. 943). O autor explica que a educação da população rural só passou a ser uma preocupação do Estado quando começou a incomodar as cidades, pois o desenvolvimento industrial, a expansão do 
comércio e o crescimento do mundo urbano demandavam uma força de trabalho alfabetizada que migrava do campo. O tipo de educação destinado às populações rurais esteve atrelado à formação de uma mão de obra "disciplinada para o trabalho assalariado rural quanto de consumidores dos produtos agropecuários gerados pelo modelo agrícola importado" (RIBEIRO, 2012, p.297). A autora acrescenta que a política educacional "contemplava interesses relacionados à expropriação da terra e à consequente proletarização dos agricultores”.

De modo geral, a escola rural é multisseriada e deveria oferecer conhecimentos elementares de leitura, escrita e matemática, porém não cumpre este objetivo, o que é atestado pelas altas taxas de analfabetismo e baixos índices de escolarização nas áreas rurais. (Idem).

Hoje, dona Neuza agradece a Deus por todos os filhos terem tido a oportunidade de frequentar a escola, pois "só não concluiu o ensino médio quem não quis". Há uma grande valorização dos estudos pela família. Cada formatura de um filho é saudada por um retrato na sala de visita. Uma das filhas preferiu o casamento ao estudo, como afirmou dona Neuza: “(...) eu falei com ela: uma coisa ou outra. Ou casamento ou estudo (...)." A instituição do casamento funciona como um ideal e representa a célula mater, por meio da qual os indivíduos desenvolvem um sentimento de pertencimento às comunidades, ao mesmo tempo em que se sentem protegidos pela instituição família, garantia de estabilidade, mesmo hoje quando os costumes e as perspectivas sociais e sexuais já não são as mesmas de tempos atrás. (TAUBE, 1992 apud CUNHA e ALVES, 2014)

Dona Neuza declarou que ensinou aos filhos o que a mãe lhe ensinou: trabalhos de casa e da roça, mas diz que os filhos não têm animo para trabalhar na roça: “(...) trabalho de roça é pesado, não é para qualquer um (...)". Os filhos estão lutando para ter uma vida diferente dos pais. Foram estudar e arranjar emprego na cidade, e a melhor opção é a submissão ao trabalho assalariado em ocupações não agrícolas, mas estão sempre voltando para a casa dos pais. Os estudos realizados por Silva (2001) mostraram que o número de famílias agrícolas está decrescendo, uma vez que elas não conseguem sobreviver somente dos rendimentos da agricultura. As famílias rurais brasileiras estão se tornando cada vez mais não agrícolas e asseguram a sobrevivência por meio de benefícios e ocupações não agrícolas. O autor acrescenta que "as terras e, acima de tudo, a casa dos pais (...) se transforma numa espécie de base territorial acolhendo cada vez mais um ponto de refúgio nas crises, especialmente do desemprego, além de permanecer como alternativa de retorno para a velhice" (SILVA, 2001, p.43). A instabilidade da vida leva os agricultores camponeses a se sujeitarem voluntariamente a uma relação assalariada.

\section{Palavras finais}

Apresentamos neste texto breves reflexões sobre a inter-relação entre as categorias trabalho, educação e divisão sexual do trabalho em comunidades rurais do município de Planalto, na Bahia. Elegemos para estudar essas categorias as narrativas de uma mulher trabalhadora rural (dona Neuza). Construímos a análise com a compreensão de que o trabalho tem uma dimensão central na vida de homens e mulheres. É por meio do trabalho, considerado como única fonte de produção de valor, que a humanidade se apropria, por meio da transformação da natureza, do que é necessário para a sobrevivência. A educação faz parte desse processo formativo de mulheres e homens do campo. Eles aprendem a trabalhar trabalhando, lidando com a natureza, relacionando-se uns com outros em diferentes espaços sociais e, por meio de práticas de trabalho, incorporam valores sobre 
trabalho, tradições culturais e construção social e histórica de gênero e, desse modo, educam as novas gerações.

Podemos conceber o trabalho e a educação como uma relação que assegura e preserva as condições objetivas de produção e reprodução da espécie humana, como salienta Mészáros (2005), ao explicar que diversas experiências de trabalho envolvem um processo contínuo de aprendizagens. Por outro lado, o mesmo autor lembra que, em uma sociedade do capital, essa relação se legitima pela exploração do trabalho e do trabalhador e se converte em trabalho assalariado precário e temporário. O trabalho assalariado materializa a exploração do homem pelo homem e a opressão das mulheres e, em consequência, as práticas educativas assumem formas de dominação.

No que diz respeito à divisão sexual do trabalho, as narrativas da história de vida evidenciam pacificação dessas relações com base na ideia da responsabilidade do trabalho doméstico como trabalho de mulher, em que o homem apenas "ajuda", e do trabalho extra doméstico como de responsabilidade do homem, de acordo com o querer ou a benevolência de cada sujeito. A ideia de situar os homens no campo produtivo, e as mulheres, no campo reprodutivo, associando aos primeiros as funções de maior valor social (KERGOAT, 2009), é desnaturalizada por meio de uma nova interpretação a respeito do trabalho. Segundo Kergoat e Hirata apud Hirata (2002), o conceito de trabalho deve ser ampliado de modo a incluir o trabalho doméstico, o trabalho não remunerado e o trabalho informal, permitindo abarcar uma massa de trabalho invisível, realizado por mulheres, nos chamando a atenção para a dimensão sexuada do trabalho.

Consideramos as comunidades estudadas como de agricultura camponesa tradicional, cujos moradores se autodenominam pequenos agricultores. Seguindo os princípios de Wanderley (1996),classificamos os moradores dessas comunidades como camponeses, e as atividades, como uma forma de campesinato. Identificamos os elementos básicos da constituição camponesa, com base nos estudos de Wanderley (1996), pelo modo de acesso à terra e de reprodução de formas particulares de produção e pela existência de meios próprios de sociabilidade.

Os relatos dos moradores sobre a historicidade da localidade foram fundamentais para estabelecimento das contradições de pertença comunitária, exemplificadas nas lembranças das precárias circunstâncias de vida e de trabalho, destacando o desenvolvimento do trabalho doméstico como uma árdua ocupação das mulheres.

A unidade de produção familiar na região visitada sofre um processo de expropriação da base fundiária, desvalorização do trabalho e precárias condições de acesso a bens materiais, sociais, culturais e econômicos. Esse processo descaracteriza a constituição original e força os mais jovens a buscarem uma inserção produtiva em atividades temporárias em outras terras ou nas cidades. Porém, os laços sociais com os vizinhos, a identidade com o lugar e o forte vínculo com a família são sempre preservados e o ciclo de vida familiar é construído, desconstruído e reconstruído por experiências educativas que demonstram uma "sociabilidade" (MARTINS, 1998) tradicional pelo lado próprio dos traços da cultura rural.

\section{Referências}

ALVES, Ana Elizabeth S. O trabalho e a educação de mulheres em comunidades rurais: práticas de reprodução social. In: BATISTA, Eraldo Leme; MULLER, Meire Terezinha. (Org.). A Educação profissional no Brasil: história, desafios e perspectivas para o século XXI.Campinas, São Paulo: Editora Alínea, 2013, v. 1, p. 235-256. 
ALVES, Ana Elizabeth S.; ALMEIDA, Miriam Cléa Coelho. A centralidade do trabalho na determinação da mobilidade territorial dos trabalhadores. Revista HISTEDBR On-line, Campinas, no 55, p. 250-266, mar, 2014 Disponível em: http://periodicos.sbu.unicamp.br/ojs/index.php/histedbr/article/viewFile/8640473/8032. Acesso em: 01/03/2014.

ALVES, Ana Elizabeth S.; ANDRADE, Daiane S.; SILVA, Rosely S.; NOVAES, Viviane A. Entrelaçando lutas pela vida: trabalho e educação de mulheres de comunidades rurais. In: Anais... XI Colóquio Nacional e IV Colóquio Internacional do Museu Pedagógico, 2015, Vitória da Conquista. Anais do Colóquio do Museu Pedagógico. Vitória da Conquista: Edições UESB, 2015. v. 11. p. 3331-3342.

BOTTOMORE, Tom. Dicionário do Pensamento Marxista. 2 ed. Rio de Janeiro: Jorge Zahar Editor, 1988.

BRUSCHINI, Cristina. Uma abordagem Sociológica de Família. Revista Brasileira de Estudos Populacionais. S.P., V.6, n.1, p. 1-23, 1989. Disponível em em: https://www.rebep.org.br/revista/article/view/562. Acesso em: 01/08/2013.

CUNHA, Tania Rocha A.; ALVES, Ana Elizabeth S. Educação e violência nas relações de gênero: reflexões na família, no casamento e na mulher. Em Aberto, v.27, p. 69-88, jul./dez.2014.

Disponível em:<http://emaberto.inep.gov.br/index.php/emaberto/article/viewFile/2447/2404>. Acesso em: 01/08/2014.

CORRÊA, Marisa. Repensando a Família Patriarcal Brasileira. In: ARANTES, A.A. et al. Colcha de retalhos: estudos sobre a família no Brasil. 3. ed. Campinas, SP: Editora da Unicamp, 1994. p. 15- 42.

CURY, Carlos Roberto J. ALGUNS APONTAMENTOS LEGAIS EM TORNO DA ÉTICA NA PESQUISA. Revista História e Perspectivas, Uberlândia, n.52, p. 39-50, jan./jul. 2015

Disponível em: $<$ http://www.seer.ufu.br/index.php/historiaperspectivas/article/view/30958/16901>.Ace sso em: 05/01/2017.

DIAS, Wilson. Agricultura familiar abastece o mercado interno e mantém empregos no campo. Entrevista. Bahia análise de dados. Salvador, v. 24, n. 2, p.223-228, abr./jun. 2014. Disponível em: <http://www.sei.ba.gov.br/images/publicacoes/sumario/aed/sumario_a\&d_agricultura_fam iliar.pdf>. Acesso em: 05/01/2017.

EVANGELISTA, Janete; MACHADO, Lucília. EDUCAÇÃO. In: MACHADO, Lucília; FIDLAGO, Fernando (Org.). Dicionário da educação profissional. Belo Horizonte: Núcleo de Estudos sobre trabalho e educação, 2000.p.118.

FERRARO, Alceu Ravanello. Alfabetização Rural no Brasil na Perspectiva das Relações Campo-Cidade e de Gênero. Revista Educação e Realidade, Porto Alegre, v. 37, n. 3, p. 943-967, set./dez. 2012. Disponível em: <www.ufrgs.br/edu_realidade>. Acesso em: 20/01/2017. 
FERREIRA, Aurélio B. de Holanda. Dicionário da Língua Portuguesa, 1975. p. 499.

FRIGOTTO, Gaudêncio; CIAVATTA, Maria. Trabalho como princípio educativo. In: CALDART, Roseli S. et al. (Org.). Dicionário da Educação do Campo. 2 ed. R.J, S.P.: Escola Politécnica de Saúde Joaquim Venâncio, Expressão Popular, 2012. p. 748-753.

KERGOAT, Danièle.Divisão sexual do trabalho e relações sociais de sexo. In:

HIRATA, Helena; et al. (Org.). Dicionário crítico feminino. São Paulo: Editora Unesp, 2009, p. 67-76.

HEYDORN, Heinz-Joachim. Elementos de uma Teoria da Educação. Revista Tempo Brasileiro - Revista de Cultura, n 17/18, 1968.

HIRATA, Helena. Nova divisão sexual do trabalho? Um olhar voltado para a empresa e a sociedade. São Paulo: Boitempo Editorial, 2002.

HIRATA, Helena; ZARIFIAN, Philippe. Trabalho (o conceito de). In: HIRATA, Helena et al. (Org.). Dicionário crítico feminino. São Paulo: Editora Unesp, 2009, p. 251-255.

IBGE. Cidades. (2003). Disponível em: <http://www.ibge.gov.br/cidadesat/topwindow.htm?1>. Acesso em: 01/09/2012.

IVO, Anete Brito L. Viver por um fio: pobreza e política social. São Paulo: Annablume; Salvador: CRH/UFBA, 2008.

LAVINAS, Lena; CODO, Barbara; VEIGA, Alinne. Bolsa Família: impacto das transferências de renda sobre a autonomia das mulheres pobres e as relações de gênero. Revista Latinoamericana de Población, Ano 6, n. 10, jan/ Jun,2012. p. 31-56. Disponível em: <http://revistarelap.org/ojs/index.php/relap/article/view/37>. Acesso em 01/11/2017.

MAIA, Cláudia J. Reprodução social camponesa. Rio Grande do Sul. Revista Mulher e Trabalho. $\quad 2004.4$ D. Disponível em: <http://www.fee.tche.br/sitefee/download/mulher/2004/artigo6.pdf>. Acesso em: 01/09/2010.

MANFREDI, S. Mª Qualificação e educação: reconstruindo nexos e inter-relações. In: SAUL, A. M.; FREITAS, J.C. (Org.). Políticas Públicas de qualificação: desafios atuais. SP: A+Comunicação, 2007. p. 9-36.

MARTINS, José de Souza. A valorização da escola e do trabalho no meio rural. In: Capitalismo e Tradicionalismo. S.P.: Biblioteca Pioneira de CiênciasSociais, 1975; p.83-100.

MARTINS, José de Souza A vida privada nas áreas de expansão da sociedade brasileira. In: NOVAIS, Fernando A.; SCHWATCZ, Lila Martiz. História da vida privada (vol 4). S.P.: Companhia das Letras, 1998. p. 659-726.

MARTINS, José de Souza. Exclusão social e a nova desigualdade. S.P.: Paulus, 2012. 
MARTINS, José de Souza. Cultura e educação na roça, encontros e desencontros. Revista USP, São Paulo, n.64, p. 28-49, dezembro/fevereiro 2004-2005. Disponível em: $<$ http://www.revistas.usp.br/revusp/issue/view/1065>. Acesso em: 15/01/2014.

MARX, K. O Capital - Crítica da Economia Política. Tradução de Regis Barbosa e Flávio R. Kothe. 2. ed. São Paulo: Nova Cultural, 1985. v. 1. (Coleção "Os economistas")

MÉSZÁROS, István. A educação para além do capital. Tradução de Isa Tavares. São Paulo: Boitempo, 2005.

MOTA, Dalva M. da; SCHMITZ, Heribert. Sobre a pertinência da categoria rural para análise do social. In: SCHMITZ, Heribert. Agricultura familiar: Extensão rural e Pesquisa Participativa. S.P: Annablume, 2010.p. 93-106.

NASCIMENTO, Carlos Alves do. Pluriatividade, Pobreza Rural e ServiçoDoméstico Remunerado. Revista de Economia. Sociologia Rural [online], v. 42, nº 02, p. 341-364, abr/jun, 2004.

Disponivel em: $<$ http://www.scielo.br/scielo.php?script=sci_arttext\&pid=S010320032004000200008>. Acesso em: 15/01/2017.

PAULILO, Maria Ignez S. O peso do trabalho leve. Revista Ciência Hoje, v.5, n.28, p. 6470, jan/fev, 1987.

Plano de Desenvolvimento do Subterritório Povo Unido. Companhia de Desenvolvimento e Ação Regional - CAR. Secretaria de Desenvolvimento e Integração Regional - SEDIR. Bahia, 2008.

QUEIROZ, Maria Isaura Pereira de. Relatos Orais: do "indizível” ao " dizível” . In: SIMSON, Olga Moraes Von. Experimentos com Histórias de Vida (Itália-Brasil). São Paulo: Vértice, 1988. p. 14-43.

RIBEIRO, Marlene. Educação Rural. In: CALDART, Roseli S. et al (Org.). Dicionário da Educação do Campo. 2 ed. R.J, S.P.: Escola Politécnica de Saúde Joaquim Venâncio, Expressão Popular, 2012. p. 293-299.

SCHNEIDE, Sergio; NIEDERLE, Paulo André. Agricultura familiar e teoria social: a diversidade das formas familiares de produção na agricultura. In: FALEIRO, Fábio Gelape; FARIAS NETO, Austeclínio Lopes. (Org.). Savanas: Desafios e Estratégias para o Equilíbrio entre Sociedade, Agronegócio e recursos naturais. Planaltina, DF: Embrapa Cerrados, 2008. p.989-1014. Disponível em: <https://www.embrapa.br/busca-depublicacoes/-/publicacao/570974/savanas-desafios-e-estrategias-para-o-equilibrio-entresociedade-agronegocio-e-recursos-naturais>. Acesso em: 10/08/2016.

SILVA, José Graziano da.Desenvolvimento Rural: Velhos e novos mitos do rural brasileiro. Revista Estudos Avançados, v. 15, n;43, S.P., set/dez. p. 1-4, 2001. Disponível em: $\quad$ http://www.scielo.br/scielo.php?script=sci_arttext\&pid=S010340142001000300005\&lng=pt\&nrm=iso Acesso em : 08/10/2014.

SILVEIRA, Ivana Teixeira. Sociedade, educação e família. Aprender - Caderno de Filosofia e Psicologia da Educação. V.C., BA, ano IV, n.7, p.149-172, 2006. 
THOMPSON, Edward. P. Tempo, disciplina de trabalho e o capitalismo industrial. In: THOMPSON, Edward. P. Costumes em comum: estudos sobre a cultura popular tradicional. São Paulo: Companhia das Letras, 2010. p. 267-304.

VÈRGES, Armando Bartra. Os novos camponeses: Leituras a partir do México profundo. Tradução M. Angélica Pandolfi. S.P.: Cultura Acadêmica; Cátedra Unesco de Educação do Campo e Desenvolvimento Rural, 2011.

WANDERLEY, $\mathrm{M}^{\mathrm{a}}$ de Nazareth Baudel. Raízes Históricas do campesinato brasileiro. XX Encontro Anual da ANPOCS. GT 17. Processos Sociais Agrários. Anais... Caxambu, MG, out, $1996 . \quad$ Disponível em: <http://www.reformaagrariaemdados.org.br/sites/default/files/Ra\%C3\%ADzes\%20Histori cas $\% 20$ do $\% 20$ Campesinato $\% 20$ Brasileiro\%20-

$\% 20$ Maria\%20de\%20Nazareth\%20Baudel\%20Wanderley\%20-\%201996.pdf>. Acesso em: 10 set. 2012.

WANDERLEY, M. de Nazareth Baudel. O mundo rural como um espaço de vida: reflexões sobre a propriedade da terra, agricultura familiar e ruralidade. Porto Alegre: UFRGS, 2009.

WEBER, M. Economia e Sociedade. Brasília: UNB, 1994.

${ }^{1}$ Doutora em educação. Docente do Departamento de Filosofia e Ciências Humanas e do Programa de PósGraduação em Memória, Linguagem e Sociedade, da Universidade Estadual do Sudoeste da Bahia (UESB). Membro do Museu Pedagógico da UESB. ana_alves183@hotmail .com

${ }^{2}$ Pesquisa financiada pelo Cnpq.

3 A Companhia de desenvolvimento e ação regional - CAR, órgão do governo estadual da Bahia, desenvolveu projeto de extensão, de 2008 a 2011, com o objetivo de ensinar e colocar em prática conhecimentos sobre quintais produtivos (para as mulheres) e criação de pequenos animais (para os homens); além disso, distribuíram mudas de plantas, incentivaram os moradores a se associarem e realizaram seminários com adultos e jovens com enfoque de gênero.

${ }^{4}$ Conforme o Plano de Desenvolvimento do Subterritório Povo Unido da Companhia de Desenvolvimento e Ação Regional - CAR. Secretaria de Desenvolvimento e Integração Regional - SEDIR. Bahia, em 2008.

${ }^{5}$ A formação social brasileira demonstra diferentes padrões de estrutura familiar, em função do tempo, do espaço e dos grupos sociais. Compreendemos, conforme explicitou Corrêa (1994) que não há um tipo universal de família brasileira (ou uma visão universalista) como modelo único e estático, mas a compreensão da categoria família em uma processualidade histórica (SILVEIRA, 2006).

Estamos compreendendo "grupo familiar" como um conjunto de pessoas que são parentes e se relacionam por meio de arranjos familiares diversificados que extrapolam as fronteiras de um domicílio, configurando um tipo de família ampliada. (BRUSCHINI, 1989).

${ }^{6}$ As pesquisas de campo foram realizadas com o apoio financeiro da Fapesb.

${ }^{7}$ Dados dessa pesquisa já foram discutidos em outros trabalho por ALVES (2013) e ALVES et al (2015).

Participaram do desenvolvimento dessa pesquisa bolsistas de iniciação científica da UESB 
8 O conceito de comunidade está inserido no conceito de relação social comunitária, constituído pelo sentimento homogêneo de pertença ao lugar (WEBER ,1994). O termo é definido como um lugar de igualdade, integração, tradição e afeto, entretanto, é importante considerar que também é um espaço de hierarquias, conflitos e resistências.

${ }^{9}$ Planta (Senna acuruensis) da região da caatinga na Bahia.

${ }^{10}$ Consideramos a história de vida como uma fonte documental primária, construída por meio de dados biográficos que relacionam as trajetórias das pessoas e as suas relações com o contexto social, conforme Queiroz (1988).

${ }^{11}$ Política focalizada de transferência de renda do governo federal, criada em 2003, para os grupos familiares marcados por alto grau de destituição e exclusão social. A política exige uma contrapartida da família, que é a comprovação da frequência escolar das crianças e a participação em programas de saúde. As mulheres são indicadas como as beneficiárias nominais do programa. (LAVINAS, COBO e VEIGA, 2012). Segundo o site da Previdência Social, a renda do Bolsa Família por pessoa varia entre R \$ 85,01 e R \$170,00 dependendo da faixa de pobreza das famílias. (Disponível em: http://novaprevidencia.com.br/bolsa-familia-quem-temdireito-ao-

beneficio/?gclid=Cj0KEQiA25rFBRC8rfyX1 vjeg7YBEiQAFIb3bwT3MhH0B_Vw5U4AZ5FraEG431tNLV yGEK0AiseRQnEaAtR38P8HAQ).

Em que pesem aos aspectos positivos do Programa Bolsa Família em "termos de sua legitimidade, alcançada pelo ineditismo da ampla cobertura, ou pelos resultados do alívio do orçamento doméstico das famílias extremamente pobres o programa, na forma como desenhado, não é um direito constitucional. Ele está submetido a decisões de manutenção e concessão da esfera burocrática” (IVO, 2008.).

12 Ajuda no sentido de complementar o trabalho do marido, o que demonstra a separação entre os trabalhos do homem e da mulher.

Recebido: Fevereiro/2017.

Aprovado: Abril/2017. 